\title{
Women Self Help Groups Enhancing Women's Development Processes in Kenya
}

\author{
Dr.Isaboke Peter Kennedy Nyataya \\ BA(HONS-SOC),MA(SOC), Mphil(SOC), Phd(SOC), Senior Lecturer, Department of Social \\ Sciences, College of Arts and Social Sciences, School of Social, Political and Administrative \\ Sciences- University of Rwanda
}

\begin{abstract}
Women self help group is not a new concept in Kenya and has existed in almost in all traditional communities in the country. The present study is on selected women self groups, operating at the grassroots in Kenya. It is a descriptive cum exploratory study. The study was undertaken with a view to understanding the members' reasons for forming the groups, the social and economic status of group members, the activities undertaken by the groups, factors for the groups'successes/failures, besides, seeking to understand their views on suitable measures for strengthening the present women's movement in Kenya. Interview; focus group discussion and observation methods were used in obtaining data from the selected respondents. Reasons for forming and joining the groups ranged from the sharing common goals to fulfilling basic needs of the rural women and to enhancing the income generating capacity of the groups through their respective activities. The respondents aged 20-50, married, comprised both men and women, were from extended families, identified themselves with the middle class, comprised both women and men, the majority of the female members was illiterate and all engaged in agriculture and agriculture related activities. The leaders of the groups were noted to be young. Majority of the members reached at least primary school and above. The groups were engaged mainly in merry-go-round, members' savings, farming and in cultural activities. Besides, the activities were viewed as opportunities for the women members to come together with a view to strengthening the ties of their sisterhood. The internal problems the groups faced include members' irregular attendance of meetings and payment of subscriptions, in addition to, leadership squabbles while external problems included lack of regular market for their farm produce, Poor and inadequate transport facilities, irregular visits by the Government officials, interference from the husbands of female members of the groups. Political parties pose a threat to the unity of the groups due their divergence and divisive views. The majority of the respondents felt that the women's movement in contemporary Kenya is very strong, committed to the sensitisation and conscientisation of women on their rights as citizens of Kenya though women still suffer from subordinate status in the society through patriarchal cultural practices. women's The respondents felt that, the leadership of the present women's movement should be in the hands of women who are youthful, well-educated, highly motivated, talented, committed, dedicated and courageous enough to take active role and participation in the various development activities of the present movement. Trainings offered on specific knowledge and skills to women leaders were singled out as essential for providing effective leadership to the movement. The findings are mainly applicable to the women self help groups included in the study and may also applied to women's groups in other regions. It is a descriptive cum exploratory study and hence, its findings are of tentative in nature and need to be re-examined. In-depth study of male members of the women's groups has not been carried out. Conclusively, it can rightly be stated that women self help groups in rural Kenya, today, serve as platforms for women to bond together as homogeneous group through meeting and sharing of common values and general interests.
\end{abstract}

Keywords: Rural Women, Culture of Saving, Self Help Groups, Income Generating Activities, Women's Development

\section{INTRODUCTION}

\section{Emergence and Development of Women Self Help Groups in Kenya}

Women, on realising that their interests are inadequately addressed in the present patriarchal society, where, allocation and implementation of power, authority and prestige, largely, rests with men, have mobilised themselves into groups in order to address common issues of women.

By organising themselves into groups, women have attempted to re-examine their present status in society, question and challenge those social values and structure which cause their marginalisation 
and formulate their strategies to improve their overall status. They strive to attain this objective by forming women/s clubs, voluntary women's associations, and various cooperatives, and where necessary, directly confront the existing authorities through roundtable dialogues, rebellions and mass movements. They also agitate discriminatory laws against women and urge the government of the day to incorporate more women in public decision making positions.

\section{LITERATURE REVIEW}

The Ministry of Culture and Social Services, Government of Kenya, defines women's groups as "a voluntary self help group with fifteen or more members made up of exclusively of women or whose membership consists of an overwhelming majority of women". This definition adds further, that, it is women who have to exercise decision making power (Report on Women Groups' Census in Nyanza Province, Kenya).

According to Nzomo, the term "women's group' generally refers to relatively small, local community-oriented female group formed for the purpose of working collectively and socialising on regular and somewhat formalised basis. The groups tend to be welfare-oriented, small and operate on the principle of self help. However, some groups are linked to international womens'organisations, which offer a channel for technical and financial assistance to the groups. A good number of them are grassroots-based and carryout projects at community level as observed in (Khasiani and Njiro, 1993:147).These groups form the building blocks of the women's movement in Kenya.

The women self help organisation is the most dominant and the most deep-rooted for of women's movement in Kenya. Other forms of organisations such as trade unions and cooperatives are of recent origin and hence, have not yet attracted, a significant women membership or activism to a comparable level as women self help groups.

Literature on women's movements in Africa has revealed that collective action is not a new thing to African women. As it is in the case of other African countries, Kenya has had a long history of women's mutual aid groups. Such groups have always existed in most of Kenya's cultural groupings, usually along kinship lines, for the purpose of sharing or celebrating occasions such as births, deaths, marriages. Besides, providing each other with communal labour be it, tilling land, planting or harvesting.

For a proper understanding of the emergence and development of the contemporary women self help groups in Kenya, a brief account of women's groups is necessary. Hence, a brief historical sketch of the emergence and development of women's groups in Kenya is presented below, which informs us about the characteristics and forms they have assumed in different historical contexts:

1. Women groups during the pre-colonial period

2. Women groups in the colonial period

3. Womens'groups in the post independent Kenya

\subsection{Women Groups During the Pre-Colonial Period}

The birth of women groups in Kenya can be traced back to the pre-colonial times, in which, Kenyan women of different ethnic background and from diverse geographical regions organised themselves on the basis of such ascriptive criteria as age, class, or territorial units. Groups such as Amasaga or Ebisangio among Abagusii,Bulala or Buhasio among the Luhya, Saga among the Luo, Ngwatio among the Gikuyu and Mwenthya among the Akamba. These are some of the examples of informal groups formed with a view to providing mutual assistance with agricultural work for coping with periodic labour shortages and hardships. In addition, the groups helped in organising funerals and childbirth support networks.

In such undertakings, every individual group member stood to benefit from this system of mutual reciprocity. Hence, the concerned could be steered towards alleviation of common problems and the attainment of desired the set up objectives.

The phase was characterised by the formation of women's groups that tended to be informal, small in membership size, based on ethnic and familial affiliation, formed for the purpose of mutual assistance and social interaction among the members of the group. 


\subsection{Women Groups in the Colonial Period}

This phase of women's group movement, largely, borrows from the traditional women groups particularly in its welfare-orientation. The groups differ from the traditional one in that they tend to be more formalised, structured and with a wider membership.

The striking feature of the colonial era is the emergence of Maendeleo Ya Wanawake Organisation (Organisation for Development of Women-MYWO) in 1952.The organisation formalised traditional informal women's' groups in Kenya. It focused mainly on women in rural areas and aimed at strengthening women's participation in rural community projects. MYWO was the first nongovernmental organisation, solely, concerned with women's affairs. It started more or less as a women's group which rapidly grew into a national organisation for women. Women's participation in development through women's groups has been an ever increasing phenomenon in Kenya since the inception of MYWO.

\subsection{Women Groups in the Post Independent Kenya}

During the period, women's groups in Kenya, grew rapidly and expanded quantitatively in terms of registered organisations. Besides, they acquire elaborate formalised structure spreading from grassroots to the national level.

Kinuthia (Khasiani and Njiro, 1993:43) observed that the post independent period witnessed the emergence of more organisations, probably, due to the fact that women realised that political independence in the country did not automatically bring improvement for them.

National Council of Women of Kenya (NCWK) came into being in 1964.It was charged with the responsibility of coordinating all other women's organisations in the country, including MYWO. NCWK seemed more dynamic and more progressive in its approach.

The international concern for women in development was clearly spelled out during the first United Nations World Conference for Women held in Mexico City in 1975, and soon after, reinforced in Copenhagen (1980) and in Nairobi (1985). In 1976, the Women's Bureau was created as national machinery for women within the structure of the Kenyan Government. One of the duties of the Bureau was the coordination of women's groups in the country. The creation of database in the women's bureau was viewed as a significant milestone in ensuring the future availability of gender based statistics for policy and planning in Kenya.

Survey of women's groups done by the Central Bureau of Statistics in 1977-78, shows that, out of 3,035 groups examined, only $1 \%$ had been formed between 1960-65 and, in 1970, $25 \%$ of the groups had been formed. $37 \%$ of the groups were started and in 1977,33\% of the groups were formed.

It is noteworthy that women's lack of access to financial resources was recognised at the Mexico City UN Conference as a constraint to family welfare and this encouraged women to initiate income generating activities such as livestock keeping, farming, handicrafts, small scale businesses to mention a few.

By 1990, the number of women's groups with the Department of Social Services, Government of Kenya, was about 29,235 with a membership of 1,135,950.

The repeal of Section 2A of the constitution of Kenya, in December 1991, opened the gateways for women's proper participation in the much needed democratisation process. Women have expressed their desire and determination to fully participate in the process and are insisting on their issues being mainstreamed in the new democratic agenda.

In 1983 national elections, twenty women councillors were elected, while, in 1992, their number increased to forty. The number of elected women members of parliament was two against seven in 1992, including one nominated.

\section{NEED FOR RESEARCHING ON WOMEN'S GROUPS IN KENYA}

The emergence and proliferation of women's groups in Kenya is a significant development in the Kenyan society as a whole. The roles of these groups in the economic, political and social spheres of Kenyan society are of great significance.

Economically, women continue to be the pillars of the Kenyan society in terms of agricultural production. In the recent times, the women groups 'original objectives and aims have changed from mutual assistance to income generating activities which have led to the rapid growth of small scale 
businesses run and managed by women. The groups have encouraged and supported women to become economically independent. Women, have also realised that, there is need for them to map out strategies and work together to lobby for the recruitment of more women in the labour paid force.

Women groups in Kenya have realised, too, that women make up more than half of the electorate in Kenya and by their numbers and they believe to have the capacity to decide on the political leadership. The groups have now identified the need for women to be integrated into the political arena. The women led organisations in the country and their leaders, have resolved to form a political forum before the next general election in Kenya. They emphasise that the platform would act as a focal point for those women who are interested in vying for presidential, parliamentary and civic elections.

Women groups have noted that as compared to men, women in Kenya occupy subordinate social status. They want to improve women' status in society. They are making every possible effort aimed at raising the status of women in Kenya at all levels. The groups have made the Kenyan society aware that discrimination against women on any basis should be discouraged and shunned. They attack cultural practices and attitudes that portray women as inherently inferior and sensitise all members of the Kenyan society to have a positive attitude towards women. The groups feel that women must be empowered at the individual level so that their self esteem is raised. They seek ways of impressing upon women that they have the right to determine what shape their future will take and make decisions to fit their plans and goals. Women in these groups are now re-examining their status in society, questioning and challenging those social values and structures which cause their marginalisation and are formulating strategies to help improve their overall status in Kenya.

Women groups and organisations in Kenya, today, have made the Kenyan society to realise that education plays a key role as it influences the level of one's participation in various national development activities including community self help projects.

Organisations such as the Forum of African Women Educationists (FAWE), are determined to help with funds to facilitate efforts to raise female participation in technical areas. The groups and organisations urge women in Kenya to view education as a socialisation process by which women are prepared to take up their respective positions within a social setting.

It is now evident that the women's groups are making significant contributions in the economic, political and social spheres of Kenyan society. Hence, there is an urgent need to undertake empirical research studies on women self help groups. However, it was found that, no studies available which exclusively focus on women groups in Kenya, at least, the researcher, did not come across any significant empirical work dealing with women self groups in Kisii County of Kenya. Hence, it was decided to conduct an empirical study work on women self help groups in Kisii County.

\section{ReSEARCh Problem AND Methodology}

\section{Statement of the Problem}

In Kenya, women self help groups have increased over the years. They are the building blocks of the women's movement in Kenya. Similarly, these groups have occupied a predominant place in Kenya social, economic and political fields. Their significance as change agents is increasing day by day. However, one finds lack of systematic research studies on these groups. In other words, there is paucity of research literature on women self groups in Kenya. Hence, the present researcher decided to undertake an empirical research on women self help groups in Kenya.

The present work mainly deals with women's groups operating at the grassroots in Kisii County. This is a descriptive cum exploratory study.

\section{OBJECTIVES OF THE STUDY}

The specific objectives of the present study are given as below:

1. To understand the objectives for forming women self help groups

2. To analyse the socio-economic conditions of the group members

3. To study the activities/functioning of the selected women self help groups

4. To identify the causes for the success/failures of the selected groups

5. To seek the respondents' views on suitable measures to for strengthening women's movement in Kenya 


\section{Research Questions}

1. What are the objectives/reasons for forming and joining women self help groups?

2. What are the social and economic conditions of the group members?

3. What are the activities undertaken by the selected women self help groups?

4. What are the causes for the successes/failures of the selected groups

5. What are the respondents' views on suitable measures for strengthening women's movement in Kenya?

\section{SCOPE OF THE STUDY}

\subsection{Geographical Area Covered}

The present study covers women self groups operating in Taraacha and Nyamware sub-locations of Keumbu Division, Kisii County.

The researcher motivated to select Kisii County for it is an area, of late, experienced the mushrooming of a good number of women self help groups, which have largely influenced the rural social and economic status of the population in the area.

In addition, women self groups in the region have yet been studied

\subsection{The Women Self Help Groups Covered Under the Present Study}

1. Taraacha women group

2. Keoke women group

3. Irondi women group

4. Riamokwobe women group

5. Aveingo women group

6. Irondi Young women group

\subsection{Respondents Selected for the Present Study}

The respondents for the present study include the leaders and the selected ordinary members of the women self help groups covered under the study.

All the office bearers, including the chairman, vice chairman, secretary, assistant secretary, treasurer or assistant treasurer were treated as leaders of these women self help groups.

\subsection{Representative Sample Size}

1. Leaders: It was decided to included all the formal leaders of selected women self help groups in the study

2. Members: It was decided to select $25 \%$ of the ordinary members belonging to each of the women self help group selected for the study

3. Total number of ordinary members of the groups was 231

\section{Methods for Data Collection}

\section{A. Interview Schedule}

An interview schedule was designed keeping in view the objectives of the present study.

\section{B. Observation Method}

The researcher attended several meetings and programmes organised by the selected women self help groups during the period of data collection.

\section{Focus Group Discussion}

The researcher organised the members of the selected groups into small groups with a view to collecting their views on the groups and respective activities 


\section{Secondary Sources of Data}

The secondary sources of data included books, articles, seminar papers and reports on Women Groups' Census in Kenya.

\section{Actual Data Collection}

Data collection for the present study commenced in the month of July and ended in the month of August 2015

\section{Data Analysis}

The collected data were tabulated manually, classified and analysed with the help of content analysis, frequency distribution and percentages were used in reporting the findings.

\section{Findings}

Following are the findings of the study:

It was noted that the main objectives /reasons for joining the women self help group were to: share common goals; fulfil basic needs of the rural women; improve the socio-economic status of the rural women; develop rural-oriented skills among rural women; raise the level of social consciousness among the poor women; improve the social, economic ,political, and cultural status of women in the area; reduce the socio-economic disparities between women and men in the area; enhance the income generating capacity of their respective women groups

The socio-economic profile of the groups reveal that the majority of the members $(90 \%)$ are in the age-group of 20-50.It was also found that all the leaders and members of all the groups under study are married and belong to extended families and, identified themselves with the middle class.It was observed that the members of these groups were both men and women, who, formed an overwhelming majority of the membership of these groups (76.6\%).Noted, too, was the fact the majority of the women are illiterate and engaged in agriculture and agriculture related activities. The leaders of the groups were noted to be younger than the ordinary members of these groups. Majority of them, $(65 \%)$ their level of education was at least primary school and above. It was also observed that the leaders have greater political participation (58\%) than ordinary members. It was noted that though the women groups covered under the present study had a uniform written constitution, the provisions in the said constitution were not strictly adhered to. To a large extent, the groups' structure was less hierarchical and more informal than in most formal organisations

It was found that the women's groups were engaged in various activities such as merry-go-round, members' contributions and savings, farming, welfare programmes, besides, cultural programmes which was noted to be the most popular programme may be due to its immediate dividends to the members. It was noted that the programmes serve as an opportunities to the members to come together and strengthen the ties of sisterhood. It was clearly observed that women's groups were not financially sound. The groups received assistance in the form of technical equipments and materials from individuals and well wishes.

It was noteworthy mentioning that the groups faced various problems ranging from operational problems to problems which originate from outside their operational areas. The internal problems that the groups face include poor attendance by members, irregular payments of fees and leadership squabbles. External problems they face include lack of market for their produce, transportation, no visits from the Kenya Government officials. Besides, the interference with the groups' affairs from members' husbands and politicians.

The majority $(60 \%)$ of the respondent felt that the women's movement in contemporary Kenya is very strong. The movement is understood to be committed to the sensitisation and conscientisation of women on their rights as citizens of Kenya. The respondents pointed out that women still suffer from subordinate status in the Kenyan society mainly due to patriarchal cultural practices, demeaning religious beliefs and practices and in addition, due to their political status as well economic status. On laws relating to women, the respondents of the view that the Kenyan laws are biased and discriminatory against women. In support of their view, they claimed that on many occasions husbands beat their wives and no law seem to be protecting them. They also claimed that the law enforcers, majority of the men, in most cases, discriminate women when executing their legal duties.

On measures to strengthen women's movement in Kenya, today, the respondents felt that, the leadership of the movement should be laid squarely in the hands of women who are youthful, well- 
educated, highly motivated, talented, committed, dedicated and courageous enough to take active role and participation in the various development activities of the present movement. Their youthfulness will enable them to serve the movement for long and at the same time, encourage more young men and women to join the movement. Dissemination of Trainings with a view to imparting specific knowledge and skills to women leaders was singled out as essential instrument for providing effective leadership to the movement.

\section{Limitations of the Present Study}

The findings are mainly applicable to the those women self help groups included in the study and could be also applied to women's groups and organisations in other regions of Kisii County. The present is an exploratory cum descriptive study one, hence, the findings are of tentative nature and need to be re-examined

In-depth study of male members of the women's groups as not carried out.

\section{CONCLusion}

Women self help groups in rural Kenya, have served as avenues not only for women for helping each other in social activities but also in enhancing economic status of its members. To a great extent, the groups have succeeded in bring huge number of women together in small, homogeneous groups that meet and share their various life experiences, concerns and a variety of social, economic and political ideas on regular basis, as demonstrated through the activities and the programmes groups covered under the present study undertake

In Kenya, today, a self help group is popularly referred as" Chama" a Kiswahili word, meaning, a 'welfare or investment group of people', 'association' or a 'merry-go-round group'. Several such groups in general and that of women have emerged and proliferated in both rural Kenya as well in urban Kenya.

As noted in the study, women in rural Kenya, join hands together with a view to helping each other to buy household facilities such as chairs, utensils, blankets, animals for rearing and even building materials, on a merry-go-round system, through their small savings and loans. It is noteworthy mentioning, here, that, today, it is observed that women self help groups, especially those in urban areas have ventured into making huge savings and formed cooperative societies and of course, this has also had spill over effects to those operating in rural areas.

The groups have spread their influence from being informal to formal in a large scale, from villages to towns and cities, from small scale contributions to large scale contributions, from large membership to small membership, probably for easy, efficient and effective management.

As observed, In Kenya, women self groups, in general, have proven their worthiness and that, if given, the deserved all-round support, coming from the Government of Kenya, professionals, willing individuals and other well-wishers, Together, may be able to identify the challenging facing groups and seek best practices that can be adopted to overcome the challenges. The aforesaid effectively, eventually, turn round the social and economic conditions of their members and their families, communities and the country in general, hence, ensuring sustainable development in Kenya.

For the present author, women self helps have been there; they are there and will continue being there for they are part and parcel of Kenya's culture.

\section{REFERENCES}

[1] Deckard,B.S (1975): The Women's Movement:Political,Socio-Economic and Psychological Issues,Harper and Row Publishers,New York

[2] Desai,N. and Maithreyi,K.(1987):Wwomen and Society in India,Ajanta Publications,New Delhi

[3] Devalatha,CM.(2005): Profile Study of Women Self Help Groups in Gadag District of Northern Karnataka

[4] Eleana La Terrara(2002):Self Help groups and Income generation in the Informal Settlement of Nairobi,Bacconi University and IGIER

[5] ESCAP(2002): Social Safety Nets for Women,United Nations Publication

[6] Feldman ,R.(1983): Women's Groups and Women's Subordination: An Analysis of Policies Towards Rural Women in Kenya, Review of African Political Economy 
[7] Khasiani,S.A. and Najiro,E.I(1993):The Women's Movement in Kenya,Association of African Women for Research and Development(AAWARD-Kenya),Nairobi

[8] Kinder Not Hilfe(2008): The Self Help Group Approach, Prajawala Enterprise,Hydrabad

[9] Mbugua-Murithi,T.(1997): Strategies for Survival in Kenya:Women Education and Self Help Groups,Internatio Journal of education Research Reform

[10] Mohindra S.K(2003): A Report on Women Self Help Groups in Kerala State,India: A Public Health Prospective, University of Montreal

[11] Puhazhendi,V.(2000):Evaluation Study of Self Help Groups in Tamil Nadu,NABARD, Mumbai

[12] Shah,K.(1984):Women's Liberation and Voluntary Action,Ajanta Publications, New Delhi

[13] Umashankar,D.(2006): Women's Empowerment Effect of Participation in Self Help Groups,Institute of Management, Bangalore 